\title{
Role of Leptin in the Activation of Immune Cells
}

\author{
Patricia Fernández-Riejos, Souad Najib, Jose Santos-Alvarez, Consuelo Martín-Romero, \\ Antonio Pérez-Pérez, Carmen González-Yanes, and Víctor Sánchez-Margalet
}

Department of Clinical Biochemistry, Virgen Macarena University Hospital, University of Seville, Av. Dr. Fedriani 3, 41071 Seville, Spain

Correspondence should be addressed to Víctor Sánchez-Margalet, margalet@us.es

Received 30 October 2009; Revised 15 January 2010; Accepted 23 January 2010

Academic Editor: Giuseppe Matarese

Copyright (C) 2010 Patricia Fernández-Riejos et al. This is an open access article distributed under the Creative Commons Attribution License, which permits unrestricted use, distribution, and reproduction in any medium, provided the original work is properly cited.

\begin{abstract}
Adipose tissue is an active endocrine organ that secretes various humoral factors (adipokines), and its shift to production of proinflammatory cytokines in obesity likely contributes to the low-level systemic inflammation that may be present in metabolic syndrome-associated chronic pathologies such as atherosclerosis. Leptin is one of the most important hormones secreted by adipocytes, with a variety of physiological roles related to the control of metabolism and energy homeostasis. One of these functions is the connection between nutritional status and immune competence. The adipocyte-derived hormone leptin has been shown to regulate the immune response, innate and adaptive response, both in normal and pathological conditions. The role of leptin in regulating immune response has been assessed in vitro as well as in clinical studies. It has been shown that conditions of reduced leptin production are associated with increased infection susceptibility. Conversely, immune-mediated disorders such as autoimmune diseases are associated with increased secretion of leptin and production of proinflammatory pathogenic cytokines. Thus, leptin is a mediator of the inflammatory response.
\end{abstract}

\section{Introduction}

White adipose tissue plays a very important role in the energetic balance of mammals. This tissue is specialized in storing lipids and supplying fuel to the whole body whenever it is necessary. In order to face energetic requirements, adipocytes regulate fatty acid mobilization in response to catabolic and anabolic stimuli. However, adipose tissue is not only a reserve organ; it is also an endocrine organ able to release hormones, peptides, and cytokines (adipokines) that affect both the energetic status and the immune system [1]. Leptin is one of the most important hormones secreted by adipose tissue [2] and its implication in energetic homeostasis at central level has been largely described [3].

Rather than a "fasting signal", leptin is a signal of starvation, in that a falling serum leptin concentration leads to neurohumoral and behavioural changes, trying to preserve energy reserves for vital functions. Thus, during fasting period and after reduction of body fat mass, there is a decrease in leptin levels that leads to a reduction in total energy expenditure to provide enough energy for the function of vital organs, that is, the brain, the heart, and the liver [4]. Even though these effects of leptin decrease are aimed to improve the survival chances under starving conditions, the fall in leptin levels may lead to immune suppression [5], in addition to other neuroendocrine alterations affecting adrenal, thyroid, and sexual/reproductive function [6]. At least, these alterations observed during fasting parallel the decrease in circulating leptin levels. In fact, both ob/ob mice (lacking leptin secretion) and $\mathrm{db} / \mathrm{db}$ mice (lacking leptin receptor) are not only obese but they also show the immune/endocrine deficiencies observed during starvation $[5,7]$. Moreover, it has been recently shown that leptin withdrawal during 8 days in experimental animals leads to the same effects regarding central control of endocrine systems including sexual function [8]. Even in humans, it has been found that leptin levels are associated with immune response in malnourished infants, which have low plasma leptin and impaired immune response [9]. Moreover, leptin signaling deficiency impairs humoral and cellular immune 
responses. The leptin receptor $\mathrm{Ob}-\mathrm{Rb}$ is expressed by $\mathrm{B}$ and T lymphocytes, suggesting that leptin regulates directly the $\mathrm{B}$ and $\mathrm{T}$ cell responses [10].

The leptin modulation of the immune system is also mediated by the regulation of hematopoiesis and lymphopoiesis [7, 11] Thus, seven days of provision of recombinant leptin promoted substantial lymphopoiesis, with a twofold increase of the numbers of $B$ cells in the marrow of obese mice while doubling and tripling, respectively, the numbers of pre-B and immature B cells. Twelve days of supplementation brought these subpopulations to near-normal proportions. Leptin treatment also facilitated myelopoiesis such that the marrow of the obese mice contained normal numbers of monocytes and granulocytes after 7 days [12].

Modulation of the immune system by leptin is exerted at the development, proliferation, antiapoptotic, maturation, and activation levels [13]. In fact, leptin receptors have been found in neutrophils, monocytes, and lymphocytes, and the leptin receptor belongs to the family of class I cytokine receptors. Moreover, leptin activates similar signaling pathways to those engaged by other members of the family [14]. The overall leptin action in the immune system is a proinflammatory effect, activating proinflammatory cells, promoting T-helper 1 responses, and mediating the production of the other proinflammatory cytokines, such as tumor necrosis factor- $\alpha$, interleukin (IL)-2, or IL-6. Leptin receptor is also upregulated by proinflammatory signals. In this paper, we will summarize data from literature that demonstrate the positive regulation of the immune response by leptin (Figure 1) [14].

\section{Leptin Activation of Innate Immunity}

The primary amino acid sequence of leptin indicated that it could belong to the long-chain helical cytokine family [15], such as IL-2, IL-12, and GH. In fact, leptin receptor (Ob-R) shows sequence homology to members of class I cytokine receptor (gp130) superfamily [16] that includes the receptor for IL-6, leucocyte inhibitory factor (LIF), and granulocyte colony-stimulating factor (G-CSF). Moreover, Ob-R has been shown to have the signaling capabilities of IL6-type cytokine receptors [16], activating JAK-STAT, PI3K, and MAPK signaling pathways [14]. In this context, a role for leptin in the regulation of innate immunity has been proposed $[14,17]$.

Consistent with this role of leptin in the mechanisms of immune response and host defense, circulating leptin levels are increased upon infectious and inflammatory stimuli such as LPS, turpentine, and cytokines $[18,19]$. On the other hand, unlike other members of the IL- 6 family, it is not clear that leptin may induce the expression of acute phase proteins, and contradictory data have been provided [19, 20]. The role of leptin regulating innate immunity has been previously reviewed [6].

2.1. Leptin Activation of Monocytes/Macrophages. Studies of rodents with genetic abnormalities in leptin or leptin receptors revealed obesity-related deficits in macrophage phagocytosis and the expression of proinflammatory cytokines both in vivo and in vitro, whereas exogenous leptin upregulated both phagocytosis and the production of cytokines [21]. Besides, phenotypic abnormalities in macrophages from leptin-deficient, obese mice have been found [22]. More importantly, leptin deficiency increases susceptibility to infectious and inflammatory stimuli and is associated with dysregulation of cytokine production [19]. More specifically, murine leptin deficiency alters Kupffer cell production of cytokines that regulate the innate immune system. In this context, leptin levels increase acutely during infection and inflammation, and may represent a protective component of the host response to inflammation [23].

Human leptin was found to stimulate proliferation and activation of human circulating monocytes in vitro, promoting the expression of activation markers: CD69, CD25, CD38, and CD71, in addition to increasing the expression of monocytes surface markers, such as HLA-DR, CD11b, and CD11c [24]. Besides, leptin potentiates the stimulatory effect of LPS or PMA on the proliferation and activation of human monocytes. Moreover, leptin dose-dependently stimulates the production of proinflammatory cytokines by monocytes, that is, TNF- $\alpha$ and IL-6 [25] and enhances CC-chemokine ligand expression in cultured murine macrophage, through activation of a JAK2-STAT3 pathway [25]. The presence of both isoforms of the leptin receptor was also assessed. Later, it was found that leptin directly induces the secretion of interleukin 1 receptor antagonist in human monocytes [26] and upregulates IP-10 (interferon-gamma-inducible protein) in monocytic cells [27]. Moreover, in human monocytes it has been shown that leptin increased both statin-inhibitable free radical and cholesterol productions in vitro [28]. In addition, it accelerates cholesteryl ester accumulation in human monocyte-derived macrophages by increasing ACAT-1 expression via JAK2 and PI3K, thereby suppressing cholesterol efflux [29]. In alveolar macrophages leptin augments leukotriene synthesis [30].

A possible role of leptin as a trophic factor to prevent apoptosis has also been found in serum-depleted human monocytes [31], which is further supporting the role of leptin as a growth factor for the monocyte. Moreover, leptin regulates monocyte function as assessed by in vitro experiments measuring free radical production. Thus, leptin was shown to stimulate the oxidative burst in control monocytes [32], and binding of leptin at the macrophage cell surface increases lipoprotein lipase expression through oxidative stress- and PKC-dependent pathways. In this line, leptin has been found to increase oxidative stress in macrophages [33]. Finally, leptin could act as a monocyte/macrophage chemoattractant inducing in vitro maximal chemotactic responses at $1 \mathrm{ng} / \mathrm{mL}$ [34], mediating the inflammatory infiltrate [35], and inducing tissue factor expression in human peripheral blood mononuclear cells [36]. On the other hand, human leptin seems to downregulate oxidative burst in previously activated monocytes [32].

Dendritic cells belong more to the same cell lineage than to monocytes/macrophages and also present leptin receptors $(\mathrm{OBRb})$ on the cell surface [37]. Thus, leptin has also been found to increase the production of IL-8, IL-12, IL-6, and TNF- $\alpha$, whereas it decreases MIP-1- $\alpha$ production 


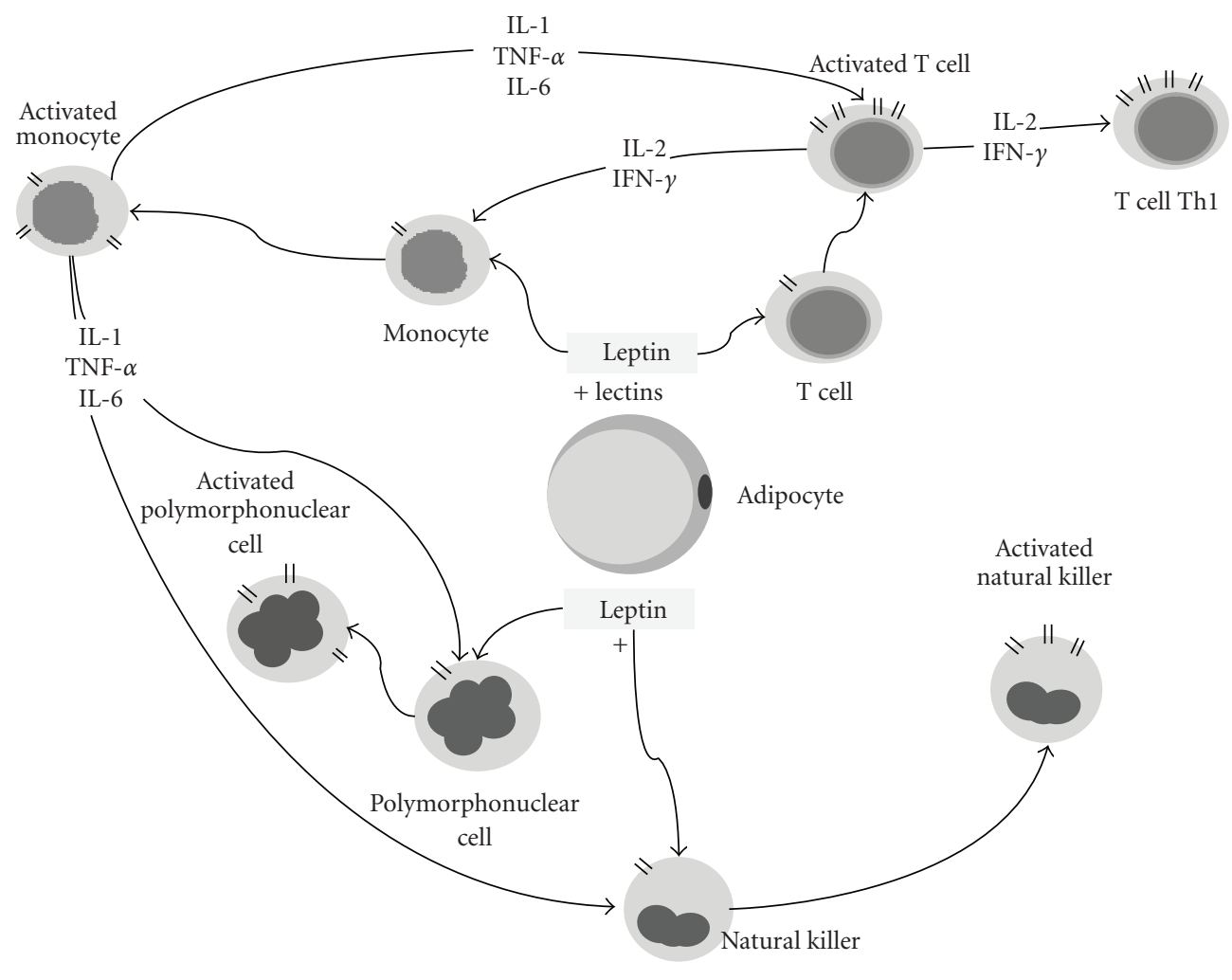

II Ob-R

FIGURE 1: Role of leptin activating immune-competent cells.

by dendritic cells. Similar to leptin effect on monocytes,it may increase the survival of dendritic cells, and it may also increase the expression of surface molecules, such as CD1a, CD80, CD83, or CD86. Leptin induces functional and morphological changes in human dendritic cells (DCs), directing them towards Th1 priming and promoting DC survival via the PI3K-Akt signaling pathway [38]. The involvement of leptin signaling in DCs survival and maturation has been observed in leptin receptor- (Ob-R-) deficient $\mathrm{db} / \mathrm{db}$ mice. $\mathrm{Db} / \mathrm{db}$ mice displayed markedly reduced expression of costimulatory molecules and a Th2-type cytokine profile, with poor capacity to stimulate allogenic T cell proliferation. Consistent with their impaired DCs phenotype and function, $\mathrm{db} / \mathrm{db}$ DCs showed significantly downregulated activities of the PI3K/Akt pathway as well as STAT-3 and IkappaB-alpha. Moreover, the reduced DCs yielded in $\mathrm{db} / \mathrm{db}$ bone marrow culture was attributed to significantly increased apoptosis, which was associated with dysregulated expression of $\mathrm{Bcl}-2$ family genes [39].

The expression of leptin and leptin receptors has been demonstrated on mast cells, suggesting paracrine and/or autocrine immunomodulatory effects of leptin on mast cells [40].

2.2. Leptin Activation of Neutrophils. Human polymorphonuclear neutrophils (PMN) have been found to express leptin receptor in vitro and in vivo [41, 42]. However, Zarkesh-Esfahani et al. [43] demonstrated that neutrophils only express the short form of the leptin receptor, which is enough to signal inside the cell, enhancing the expression of CD11b and preventing apoptosis $[42,43]$. Leptin delayed the cleavage of Bid and Bax, the mitochondrial release of cytochrome $\mathrm{c}$ and second mitochondria-derived activator of caspase, as well as the activation of both caspase- 8 and caspase- 3 in these cells [42]. Therefore, leptin seems to behave as a survival cytokine for PMN, similar to G-CSF.

Leptin promotes neutrophils chemotaxis [19, 44]. In fact, the chemoattractant effect is comparable to that of well-known formyl-methionyl-leucyl-phenylalanine (FMLP). Otherwise, when leptin acts as a uremic toxin it interferes with neutrophil chemotaxis [45] and inhibits neutrophil migration in response to classical neutrophilic chemoattractants and leptin is endowed with chemotactic activity toward neutrophils. The two activities, inhibition of the cell response to chemokines and stimulation of neutrophil migration, could be detected at similar concentrations. On the contrary, neutrophils exposed to leptin did not display detectable $[\mathrm{Ca} 2+]$ i mobilization, oxidant production, or beta2-integrin upregulation [46].

Moreover, leptin also has a stimulating effect on intracellular hydrogen peroxide production in PMN although this effect seems to be mediated by the activation of monocytes [42]. More specifically, leptin modulates neutrophil phagocytosis of Klebsiella pneumoniae [47] and in diabetic patients' neutrophils, an increase in leptin serum levels has been correlated with the degree of CD11b expression [48]. 
On eosinophils, leptin could upregulate cell surface expression of adhesion molecules ICAM-1 and CD18 but suppress ICAM-3 and L-selectin. Moreover, leptin could also stimulate the chemokinesis of eosinophils and induce the release of inflammatory cytokines IL-1beta and IL- 6 and chemokines IL-8, growth-related oncogene-alpha, and MCP1 [49].

2.3. Natural Killer (NK) Cells. Human NK cells constitutively express both long and short forms of $\mathrm{Ob}$ receptor. Moreover, the leptin receptors can signal in NK cells, since leptin activates STAT3 phosphorylation in NK cells. Moreover, leptin increases IL-2 and perforin gene expression at the transcription levels in NK cells. Consistent with this role of leptin regulating $\mathrm{NK}$ cells, $\mathrm{db} / \mathrm{db}$ mice have been found to have impaired NK cell function $[50,51]$.

Leptin actions in NK cells include cell maturation, differentiation, activation, and cytotoxicity [20]. Leptin enhances both the development and the activation of NK cells [50], increasing IL-12 and reducing the expression of IL-15 [51]. Besides, leptin mediates the activation of NK cells indirectly by modulation of IL- $1 \beta$, IL- 6 , and TNF- $\alpha$ by monocytes and macrophages [36].

\section{Leptin Modulation of Adaptive Immune Response}

The role of leptin in cell-mediated immunity has been obtained working with ob/ob mice [18]. These mice have a decreased sensitivity of $\mathrm{T}$ cells to activating stimuli. Besides, these animals show atrophy of lymphoid organs [5-7], with a decrease in the number of circulating $\mathrm{T}$ cells and an increase in the number of monocytes. Besides, ob/ob mice have a decrease in the number of TNKCD4+ in the liver [52]. The ability of leptin preventing thymic atrophia is due to a direct antiapoptotic effect on T cells [7]. Thus, leptin treatment increases thymic expression of interleukin7, an important soluble thymocyte growth factor produced by medullary thymic epithelial cells (TECs). The hormone leptin has an intrathymic role in maintaining healthy thymic epithelium and promoting thymopoiesis, which is revealed when thymus homeostasis is perturbed by endotoxemia. In this case, leptin treatment decreases in vivo apoptosis of double positive thymocytes and promotes proliferation of double negative thymocytes [53].

In the thymus, Fyn acts as a tyrosine kinase that transduces the leptin signal independently of JAK2 activation and mediates some of the immunomodulatory effects of leptin in this tissue. The tyrosine kinase, Fyn, is constitutively associated with the Ob-R in thymic cells. Following a leptin stimulus, Fyn undergoes an activating tyrosine phosphorylation and a transient association with IRS1 [54].

Acute deficiency of leptin has a potent effect on the immune system, which is even higher than that observed in ob/ob mice (genetic defect). Acute hypoleptinemic mice show a higher decrease in the total number of thymocytes, and double number of apoptotic cells than ob/ob mice. Moreover, the acute deficiency of leptin also causes a decrease in splenic cellularity, which does not occur in ob/ob mice, even though they have a smaller spleen than control mice [8]. Both ob/ob and db/db mice show defects in cell-mediated immune response which lead to impaired reaction of delayed hypersensibility, suppression of skin allograft rejection, and inhibition of footpad swelling by recall antigens $[6,55-$ 57]. In recent studies, leptin enhanced in vivo lymphocyte proliferation in Siberian hamsters (Phodopus sungorus) and increased splenocyte proliferation in mice [58] as well as it increased percentage of $\mathrm{T}$ cells, particularly CD4+ Th cells, in peritoneal fluid of patients with endometriosis [59].

Lord et al. 1998 [5], demonstrated that mouse lymphocytes express the long form of leptin receptor, and that leptin modulates in these cells cytokine production. Besides, leptin also regulates the number and activation of $\mathrm{T}$ lymphocytes. The proliferative response to leptin in mice seems to be produced in naive $\mathrm{T}$ cells $(\mathrm{CD} 4+\mathrm{CD} 45 \mathrm{RA}+)$, whereas it has been shown that leptin inhibits proliferation of memory $\mathrm{T}$ cells $(\mathrm{CD} 4+\mathrm{CD} 45 \mathrm{RO}+)$ [5]. Leptin provides a survival signal in double positive $\mathrm{T}$ cells $(\mathrm{CD} 4+\mathrm{CD} 8+)$ and simple positive $\mathrm{CD} 4+\mathrm{CD} 8$ - thymocytes during thymic maturation [7]. In addition, leptin promotes the expression of adhesion molecules in CD4+ T cells, such as VLA-2 (CD49b) or ICAM-1 (CD54) $[5,18]$.

More recently, we have reviewed the role of human leptin on T cell response [14]. Human leptin alone is not able to activate human peripheral blood lymphocytes in vitro [23] even though leptin receptor is present and activated in T lymphocytes upon leptin stimulation, fully triggering the intracellular signal transduction, as we have also assessed [60, 61]. However, when $T$ lymphocytes are costimulated with PHA or concanavalin A (Con A), leptin dose-dependently enhances the proliferation and activation of cultured T lymphocytes, achieving maximal effect at $10 \mathrm{nM}$ concentration [62]. Thus, leptin increases the expression of early activation markers such as CD69, as well as the expression of late activation markers, such as CD25, or CD71 in both CD4+ and CD8+ T lymphocytes in the presence of suboptimal concentrations of activators such as PHA $(2 \mu \mathrm{g} / \mathrm{mL})$ and after stimulation with PMA-ionomycin [63]. However, when maximal concentrations of PHA or Con A are employed, leptin has no further effect. These effects of leptin on $\mathrm{T}$ lymphocytes are observed even in the absence of monocytes, suggesting a direct effect of human leptin on circulating $\mathrm{T}$ lymphocytes when they are costimulated [62]. The activation of $\mathrm{T}$ cells induces the expression of the long isoform of the $\mathrm{Ob}$ receptor [63]. The need for costimulation with mitogens to get the effect of leptin in lymphocytes may be partly explained by this effect of activation, increasing leptin receptor expression in T lymphocytes. Besides, these data suggest that the leptin receptor may be regulated in a similar way to other cytokine receptors, such as the IL-2 receptor (CD25).

Human leptin not only modulates the activation and proliferation of human $\mathrm{T}$ lymphocytes but also enhances cytokine production induced by submaximal concentrations of PHA [62]. Thus, human leptin enhances the production of IL-2 and IFN- $\gamma$ in stimulated T lymphocytes. It had been previously shown in mice that leptin can enhance cognate 
$\mathrm{T}$ cell response, skewing cytokine responses towards a Th1 phenotype in mice [5]. These data are in agreement with the observation of the leptin effect on anti-CD 3 stimulation of $\mathrm{T}$ cells, which increases the production of the proinflammatory cytokine IFN- $\gamma$ [64]. The effect of leptin polarizing T cells towards a Th1 response seems to be mediated by stimulating the synthesis of IL-2, IL-12, and IFN-gamma and the inhibition of the production of IL-10 and IL-4 [36, 62]. Th1 polarization has been correlated with hyperleptinemia in hemodialysis patients [65] and the protection of ob/ob mice in Th1- as well as in Th2-dependent inflammation is provided by a decreased expression of the key transcription factors for Th1 and Th2 polarization, T-bet and GATA-3 in naive ob/ob T cells. In this case, leptin was found to be necessary in T-helper 1- (Th1-) dependent inflammatory processes acting as a critical regulator of $\mathrm{CD} 4+\mathrm{T}$ cell polarization in vitro and in vivo [66]. These data regarding leptin modulation of Th1-type cytokine production are in line with the observed effects of leptin stimulating TNF- $\alpha$ and IL- 6 production by monocytes [24], further suggesting the possible role of human leptin in the regulation of the immune system inducing a proinflammatory response. On peripheral blood mononuclear cells of patients with ankylosing spondylitis, leptin exerts proinflammatory effect [67] as well as it enhances the proinflammatory cytokines in normal colonocytes and in HT29 xenografted tumor colonocytes. Colonocyte-derived products after leptin treatment stimulated perforin and granzyme B expressions in normal CD8 (+) T cells in vitro [68]. In addition, leptin alone or in combination with IL-1 enhanced the expression of iNOS and COX-2 and production of NO, PGE (2), IL-6, and IL8. The effects of leptin are mediated through activation of transcription factor nuclear factor-kappaB (NF-kappaB) and mitogen-activated protein kinase (MAPK) pathway c-Jun $\mathrm{NH}$ (2)-terminal kinase (JNK).The increased synthesis of proinflammatory mediators is mediated by nitric oxide (NO) in human osteoarthritic cartilage [69].

On the other hand, leptin promotes $\mathrm{T}$ cell survival and Jurkat $\mathrm{T}$ lymphocytes survival [70] by modulating the expression of antiapoptotic proteins, such as Bcl-xL in stressinduced apoptosis [71]. This trophic effect of leptin on $\mathrm{T}$ cell is consistent with the reduction in lymphocyte numbers observed in fasted mice, that might be explained by the acute decrease in leptin levels $[7,19]$. The role of leptin modulating $\mathrm{T}$ cell function in humans has been finally defined by clinical studies in specific and rare cases of patients with monogenic obesity. In human obesity due to congenital leptin deficiency, there is a $\mathrm{T}$ cell hyporesponsiveness (in addition to the expected neuroendocrine/metabolic dysfunction), and not only leptin treatment in these patients is an effective lowering body weight but it can also revert $\mathrm{T}$ cell response to mitogen activation in vitro [72]. In addition, leptin has been necessary in nonagenarians ( $\geq 90$ years old) to maintain functional naive CD8 T cells and a healthy immune system [73].

The leptin receptor is highly expressed on the cell surface of Tregs. Leptin can act as a negative signal for the proliferation of human Foxp3 (+) CD4 (+) CD25 (+) regulatory $\mathrm{T}(\mathrm{T}(\mathrm{reg}))$ cells. In vitro, neutralization with leptin monoclonal antibody (mAb), during anti-CD3 and
anti-CD28 stimulation, resulted in $\mathrm{T}(\mathrm{reg})$ cell proliferation, which was interleukin-2 (IL-2) dependent. Together with the finding of enhanced proliferation of $\mathrm{T}(\mathrm{reg})$ cells observed in leptin- and ObR-deficient mice, these results suggest a potential for therapeutic interventions in immune and autoimmune diseases [74].

\section{Conclusions}

In conclusion, leptin plays a role in the activation of the immune system, and it is a mediator of inflammation. In this context, leptin may be one of the mediators responsible for the low-level systemic inflammation that may be present in metabolic syndrome-associated chronic pathologies such as atherosclerosis, which is associated with obesity, especially central obesity. Therefore, leptin may be considered as a therapeutic target in some clinical situations, such as proinflammatory states or autoimmune diseases, to control an excess of immune response, as well as in other clinical situations, such as starving, to control an excess of exercise, or immune deficiencies, to improve the impaired immune response. That is why the investigation of the role of leptin in the regulation of the immune response remains a challenge for the future.

\section{References}

[1] S. E. Wozniak, L. L. Gee, M. S. Wachtel, and E. E. Frezza, "Adipose tissue: the new endocrine organ? A review article," Digestive Diseases and Sciences, vol. 54, no. 9, pp. 1847-1856, 2009.

[2] Y. Zhang, R. Proenca, M. Maffei, M. Barone, L. Leopold, and J. M. Friedman, "Positional cloning of the mouse obese gene and its human homologue," Nature, vol. 372, no. 6505, pp. 425432, 1994.

[3] J. S. Flier, "The adipocyte: storage depot or node on the energy information superhighway?" Cell, vol. 80, no. 1, pp. 15-18, 1995.

[4] R. S. Ahima, D. Prabakaran, C. Mantzoros, et al., "Role of leptin in the neuroendocrine response to fasting," Nature, vol. 382, no. 6588, pp. 250-252, 1996.

[5] G. M. Lord, G. Matarese, J. K. Howard, R. J. Baker, S. R. Bloom, and R. I. Lechler, "Leptin modulates the T-cell immune response and reverses starvation- induced immunosuppression," Nature, vol. 394, no. 6696, pp. 897-901, 1998.

[6] G. Fantuzzi and R. Faggioni, "Leptin in the regulation of immunity, inflammation, and hematopoiesis," Journal of Leukocyte Biology, vol. 68, no. 4, pp. 437-446, 2000.

[7] J. K. Howard, G. M. Lord, G. Matarese, et al., "Leptin protects mice from starvation-induced lymphoid atrophy and increases thymic cellularity in ob/ob mice," The Journal of Clinical Investigation, vol. 104, no. 8, pp. 1051-1059, 1999.

[8] J. M. Montez, A. Soukas, E. Asilmaz, G. Fayzikhodjaeva, G. Fantuzzi, and J. M. Friedman, "Acute leptin deficiency, leptin resistance, and the physiologic response to leptin withdrawal," Proceedings of the National Academy of Sciences of the United States of America, vol. 102, no. 7, pp. 2537-2542, 2005.

[9] A. Palacio, M. Lopez, F. Perez-Bravo, F. Monkeberg, and L. Schlesinger, "Leptin levels are associated with immune response in malnourished infants," Journal of Clinical 
Endocrinology and Metabolism, vol. 87, no. 7, pp. 3040-3046, 2002.

[10] N. Busso, A. So, V. Chobaz-Péclat, et al., "Leptin signaling deficiency impairs humoral and cellular immune responses and attenuates experimental arthritis," Journal of Immunology, vol. 168, no. 2, pp. 875-882, 2002.

[11] B. D. Bennett, G. P. Solar, J. Q. Yuan, J. Mathias, G. R. Thomas, and W. Matthews, "A role for leptin and its cognate receptor in hematopoiesis," Current Biology, vol. 6, no. 9, pp. 1170-1180, 1996.

[12] K. Claycombe, L. E. King, and P. J. Fraker, "A role for leptin in sustaining lymphopoiesis and myelopoiesis," Proceedings of the National Academy of Sciences of the United States of America, vol. 105, no. 6, pp. 2017-2021, 2008.

[13] A. Stofkova, "Leptin and adiponectin: from energy and metabolic dysbalance to inflammation and autoimmunity," Endocrine Regulations, vol. 43, no. 4, pp. 157-168, 2009.

[14] V. Sánchez-Margalet, C. Martín-Romero, J. Santos-Alvarez, R. Goberna, S. Najib, and C. Gonzalez-Yanes, "Role of leptin as an immunomodulator of blood mononuclear cells: mechanisms of action," Clinical and Experimental Immunology, vol. 133, no. 1, pp. 11-19, 2003.

[15] T. Madej, M. S. Boguski, and S. H. Bryant, "Threading analysis suggests that the obese gene product may be a helical cytokine," FEBS Letters, vol. 373, no. 1, pp. 13-18, 1995.

[16] L. A. Tartaglia, M. Dembski, X. Weng, et al., "Identification and expression cloning of a leptin receptor, OB-R," Cell, vol. 83, no. 7, pp. 1263-1271, 1995.

[17] G. M. Lord, G. Matarese, J. K. Howard, and R. I. Lechler, "The bioenergetics of the immune system," Science, vol. 292, no. 5518, pp. 855-856, 2001.

[18] G. Matarese, "Leptin and the immune system: how nutritional status influences the immune response," European Cytokine Network, vol. 11, no. 1, pp. 7-13, 2000.

[19] R. Faggioni, K. R. Feingold, and C. Grunfeld, "Leptin regulation of the immune response and the immunodeficiency of malnutrition," FASEB Journal, vol. 15, no. 14, pp. 2565-2571, 2001.

[20] G. Matarese, S. Moschos, and C. S. Mantzoros, "Leptin in immunology," Journal of Immunology, vol. 174, no. 6, pp. 3137-3142, 2005.

[21] S. Loffreda, S. Q. Yang, H. Z. Lin, et al., "Leptin regulates proinflammatory immune responses," FASEB Journal, vol. 12, no. 1, pp. 57-65, 1998.

[22] F.-Y. J. Lee, Y. Li, E. K. Yang, et al., "Phenotypic abnormalities in macrophages from leptin-deficient, obese mice," American Journal of Physiology, vol. 276, no. 2, pp. C386-C394, 1999.

[23] P. Sarraf, R. C. Frederich, E. M. Turner, et al., "Multiple cytokines and acute inflammation raise mouse leptin levels: potential role in inflammatory anorexia," Journal of Experimental Medicine, vol. 185, no. 1, pp. 171-175, 1997.

[24] J. Santos-Alvarez, R. Goberna, and V. Sánchez-Margalet, "Human leptin stimulates proliferation and activation of human circulating monocytes," Cellular Immunology, vol. 194, no. 1, pp. 6-11, 1999.

[25] N. Kiguchi, T. Maeda, Y. Kobayashi, Y. Fukazawa, and S. Kishioka, "Leptin enhances CC-chemokine ligand expression in cultured murine macrophage," Biochemical and Biophysical Research Communications, vol. 384, no. 3, pp. 311-315, 2009.

[26] C. Gabay, M. G. Dreyer, N. Pellegrinelli, R. Chicheportiche, and C. A. Meier, "Leptin directly induces the secretion of interleukin 1 receptor antagonist in human monocytes," Journal of Clinical Endocrinology and Metabolism, vol. 86, no. 2, pp. 783-791, 2001.

[27] C. A. Meier, R. Chicheportiche, M. Dreyer, and J.-M. Dayer, "IP-10, but not RANTES, is upregulated by leptin in monocytic cells," Cytokine, vol. 21, no. 1, pp. 43-47, 2003.

[28] Z. Balogh, G. Fóris, B. Kosztáczky, et al., "The concentration dependent biphasic effect of leptin on endogenous cholesterol synthesis in human monocytes," Peptides, vol. 28, no. 10, pp. 2081-2083, 2007.

[29] S. Hongo, T. Watanabe, S. Arita, et al., "Leptin modulates ACAT1 expression and cholesterol efflux from human macrophages," American Journal of Physiology, vol. 297, no. 2, pp. E474-E482, 2009.

[30] P. Mancuso, C. Canetti, A. Gottschalk, P. K. Tithof, and M. Peters-Golden, "Leptin augments alveolar macrophage leukotriene synthesis by increasing phospholipase activity and enhancing group IVC iPLA (cPLA $\left._{2} \gamma\right)$ protein expression," American Journal of Physiology, vol. 287, no. 3, pp. L497-L502, 2004.

[31] S. Najib and V. Sánchez-Margalet, "Human leptin promotes survival of human circulating blood monocytes prone to apoptosis by activation of p42/44 MAPK pathway," Cellular Immunology, vol. 220, no. 2, pp. 143-149, 2002.

[32] C. Sánchez-Pozo, J. Rodriguez-Baño, A. DomínguezCastellano, M. A. Muniain, R. Goberna, and V. SánchezMargalet, "Leptin stimulates the oxidative burst in control monocytes but attenuates the oxidative burst in monocytes from HIV-infected patients," Clinical and Experimental Immunology, vol. 134, no. 3, pp. 464-469, 2003.

[33] F. Maingrette and G. Renier, "Leptin increases lipoprotein lipase secretion by macrophages: involvement of oxidative stress and protein kinase C," Diabetes, vol. 52, no. 8, pp. 21212128, 2003.

[34] M. L. Gruen, M. Hao, D. W. Piston, and A. H. Hasty, "Leptin requires canonical migratory signaling pathways for induction of monocyte and macrophage chemotaxis," American Journal of Physiology, vol. 293, no. 5, pp. C1481-C1488, 2007.

[35] C. A. Curat, A. Miranville, C. Sengenès, et al., "From blood monocytes to adipose tissue-resident macrophages: induction of diapedesis by human mature adipocytes," Diabetes, vol. 53, no. 5, pp. 1285-1292, 2004.

[36] E. Napoleone, A. Di Santo, C. Amore, et al., "Leptin induces tissue factor expression in human peripheral blood mononuclear cells: a possible link between obesity and cardiovascular risk?" Journal of Thrombosis and Haemostasis, vol. 5, no. 7, pp. 1462-1468, 2007.

[37] B. Mattioli, E. Straface, M. G. Quaranta, L. Giordani, and M. Viora, "Leptin promotes differentiation and survival of human dendritic cells and licenses them for Th1 priming," Journal of Immunology, vol. 174, no. 11, pp. 6820-6828, 2005.

[38] B. Mattioli, L. Giordani, M. G. Quaranta, and M. Viora, "Leptin exerts an anti-apoptotic effect on human dendritic cells via the PI3K-Akt signaling pathway," FEBS Letters, vol. 583, no. 7, pp. 1102-1106, 2009.

[39] Q. L. K. Lam, S. Liu, X. Cao, and L. Lu, "Involvement of leptin signaling in the survival and maturation of bone marrowderived dendritic cells," European Journal of Immunology, vol. 36, no. 12, pp. 3118-3130, 2006.

[40] J. Taildeman, C. A. Pérez-Novo, I. Rottiers, et al., "Human mast cells express leptin and leptin receptors," Histochemistry and Cell Biology, vol. 131, no. 6, pp. 703-711, 2009. 
[41] F. Caldefie-Chezet, A. Poulin, A. Tridon, B. Sion, and M.-P. Vasson, "Leptin: a potential regulator of polymorphonuclear neutrophil bactericidal action?" Journal of Leukocyte Biology, vol. 69, no. 3, pp. 414-418, 2001.

[42] A. Bruno, S. Conus, I. Schmid, and H.-U. Simon, "Apoptotic pathways are inhibited by leptin receptor activation in neutrophils," Journal of Immunology, vol. 174, no. 12, pp. 8090 8096, 2005.

[43] H. Zarkesh-Esfahani, A. G. Pockley, Z. Wu, P. G. Hellewell, A. P. Weetman, and R. J. M. Ross, "Leptin indirectly activates human neutrophils via induction of TNF- $\alpha$," Journal of Immunology, vol. 172, no. 3, pp. 1809-1814, 2004.

[44] F. Caldefie-Chezet, A. Poulin, and M.-P. Vasson, "Leptin regulates functional capacities of polymorphonuclear neutrophils," Free Radical Research, vol. 37, no. 8, pp. 809-814, 2003.

[45] L. Ottonello, P. Gnerre, M. Bertolotto, et al., "Leptin as a uremic toxin interferes with neutrophil chemotaxis," Journal of the American Society of Nephrology, vol. 15, no. 9, pp. 23662372, 2004.

[46] F. Montecucco, G. Bianchi, P. Gnerre, M. Bertolotto, F. Dallegri, and L. Ottonello, "Induction of neutrophil chemotaxis by leptin: crucial role for p38 and Src kinases," Annals of the New York Academy of Sciences, vol. 1069, pp. 463-471, 2006.

[47] S. I. Moore, G. B. Huffnagle, G.-H. Chen, E. S. White, and P. Mancuso, "Leptin modulates neutrophil phagocytosis of Klebsiella pneumoniae," Infection and Immunity, vol. 71, no. 7, pp. 4182-4185, 2003.

[48] K. Mastej and R. Adamiec, "Neutrophil surface expression of adhesion molecule CD11b in patients with type 2 diabetes," Przegląd Lekarski, vol. 66, no. 5, pp. 228-232, 2009.

[49] C. K. Wong, P. F.-Y. Cheung, and C. W.-K. Lam, "Leptinmediated cytokine release and migration of eosinophils: implications for immunopathophysiology of allergic inflammation," European Journal of Immunology, vol. 37, no. 8, pp. 2337-2348, 2007.

[50] Z. Tian, R. Sun, H. Wei, and B. Gao, "Impaired natural killer (NK) cell activity in leptin receptor deficient mice: leptin as a critical regulator in NK cell development and activation," Biochemical and Biophysical Research Communications, vol. 298, no. 3, pp. 297-302, 2002.

[51] Y. Zhao, R. Sun, L. You, C. Gao, and Z. Tian, "Expression of leptin receptors and response to leptin stimulation of human natural killer cell lines," Biochemical and Biophysical Research Communications, vol. 300, no. 2, pp. 247-252, 2003.

[52] A. La Cava and G. Matarese, "The weight of leptin in immunity," Nature Reviews Immunology, vol. 4, no. 5, pp. 371379,2004

[53] A. L. Gruver, M. S. Ventevogel, and G. D. Sempowski, "Leptin receptor is expressed in thymus medulla and leptin protects against thymic remodeling during endotoxemiainduced thymus involution," The Journal of Endocrinology, vol. 203, no. 1, pp. 75-85, 2009.

[54] A. Girasol, G. G. Albuquerque, E. Mansour, et al., "Fyn mediates leptin actions in the thymus of rodents," PLoS One, vol. 4, no. 11, article e7707, 2009.

[55] Z. Li, H. Lin, S. Yang, and A. M. Diehl, "Murine leptin deficiency alters Kupffer cell production of cytokines that regulate the innate immune system," Gastroenterology, vol. 123, no. 4, pp. 1304-1310, 2002.

[56] M. Guebre-Xabier, S. Yang, H. Z. Lin, R. Schwenk, U. Krzych, and A. M. Diehl, "Altered hepatic lymphocyte subpopulations in obesity-related murine fatty livers: potential mechanism for sensitization to liver damage," Hepatology, vol. 31, no. 3, pp. 633-640, 2000.
[57] M. A. Mandel and A. A. F. Mahmoud, "Impairment of cell-mediated immunity in mutation diabetic mice $(\mathrm{db} / \mathrm{db})$," Journal of Immunology, vol. 120, no. 4, pp. 1375-1377, 1978.

[58] G. E. Demas, "In vivo but not in vitro leptin enhances lymphocyte proliferation in Siberian hamsters (Phodopus sungorus)," General and Comparative Endocrinology, vol. 166, no. 2, pp. 314-319, 2010.

[59] Ł. Milewski, E. Barcz, P. Dziunycz, et al., "Association of leptin with inflammatory cytokines and lymphocyte subpopulations in peritoneal fluid of patients with endometriosis," Journal of Reproductive Immunology, vol. 79, no. 1, pp. 111-117, 2008.

[60] V. Sanchez-Margalet and C. Martin-Romero, "Human leptin signaling in human peripheral blood mononuclear cells: activation of the JAK-STAT pathway," Cellular Immunology, vol. 211, no. 1, pp. 30-36, 2001.

[61] C. Martín-Romero and V. Sánchez-Margalet, "Human leptin activates PI3K and MAPK pathways in human peripheral blood mononuclear cells: possible role of Sam68," Cellular Immunology, vol. 212, no. 2, pp. 83-91, 2001.

[62] C. Martín-Romero, J. Santos-Alvarez, R. Goberna, and V. Sánchez-Margalet, "Human leptin enhances activation and proliferation of human circulating T lymphocytes," Cellular Immunology, vol. 199, no. 1, pp. 15-24, 2000.

[63] V. Sánchez-Margalet, C. Martín-Romero, C. González-Yanes, R. Goberna, J. Rodríguez-Baño, and M. A. Muniain, "Leptin receptor (Ob-R) expression is induced in peripheral blood mononuclear cells by in vitro activation and in vivo in HIVinfected patients," Clinical and Experimental Immunology, vol. 129, no. 1, pp. 119-124, 2002.

[64] G. M. Lord, G. Matarese, J. K. Howard, S. R. Bloom, and R. I. Lechler, "Leptin inhibits the anti-CD3-driven proliferation of peripheral blood $\mathrm{T}$ cells but enhances the production of proinflammatory cytokines," Journal of Leukocyte Biology, vol. 72, no. 2, pp. 330-338, 2002.

[65] M.-L. Liu, Z.-Y. Huang, X.-C. Zhong, et al., "Th1 polarization and low-T3 syndrome are correlated with hyperleptinemia in hemodialysis patients," Journal of Nephrology, vol. 22, no. 4, pp. 515-522, 2009.

[66] A. Batra, B. Okur, R. Glauben, et al., "Leptin: a critical regulator of $\mathrm{CD}^{+}$T-cell polarization in vitro and in vivo," Endocrinology, vol. 151, no. 1, pp. 56-62, 2010.

[67] M.-C. Park, S.-J. Chung, Y.-B. Park, and S.-K. Lee, "Proinflammatory effect of leptin on peripheral blood mononuclear cells of patients with ankylosing spondylitis," Joint Bone Spine, vol. 76, no. 2, pp. 170-175, 2009.

[68] M. Abolhassani, N. Aloulou, M. T. Chaumette, et al., "Leptin receptor-related immune response in colorectal tumors: the role of colonocytes and interleukin-8," Cancer Research, vol. 68, no. 22, pp. 9423-9432, 2008.

[69] E. Moilanen, K. Vuolteenaho, A. Koskinen, et al., "Leptin enhances synthesis of proinflammatory mediators in human osteoarthritic cartilage-mediator role of NO in leptininduced PGE 2, IL-6, and IL-8 production," Mediators of Inflammation, vol. 2009, Article ID 345838, 10 pages, 2009.

[70] P. Fernández-Riejos, R. Goberna, and V. Sánchez-Margalet, "Leptin promotes cell survival and activates Jurkat T lymphocytes by stimulation of mitogen-activated protein kinase," Clinical and Experimental Immunology, vol. 151, no. 3, pp. 505-518, 2008.

[71] Y. Fujita, M. Murakami, Y. Ogawa, et al., "Leptin inhibits stress-induced apoptosis of T lymphocytes," Clinical and Experimental Immunology, vol. 128, no. 1, pp. 21-26, 2002.

[72] I. S. Farooqi, G. Matarese, G. M. Lord, et al., "Beneficial effects of leptin on obesity, $\mathrm{T}$ cell hyporesponsiveness, and 
neuroendocrine/metabolic dysfunction of human congenital leptin deficiency," The Journal of Clinical Investigation, vol. 110, no. 8, pp. 1093-1103, 2002.

[73] J. Chen, J. Li, F. C. Lim, et al., "Maintenance of naïve CD8 T cells in nonagenarians by leptin, IGFBP3 and T3," Mechanisms of Ageing and Development, vol. 131, no. 1, pp. 29-37, 2010.

[74] G. Matarese, V. De Rosa, and A. La Cava, "Regulatory CD4 T cells: sensing the environment," Trends in Immunology, vol. 29, no. 1 , pp. $12-17,2008$. 


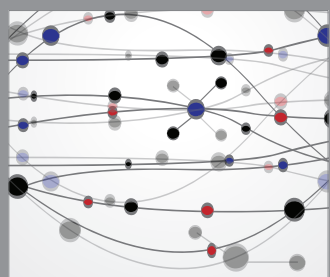

The Scientific World Journal
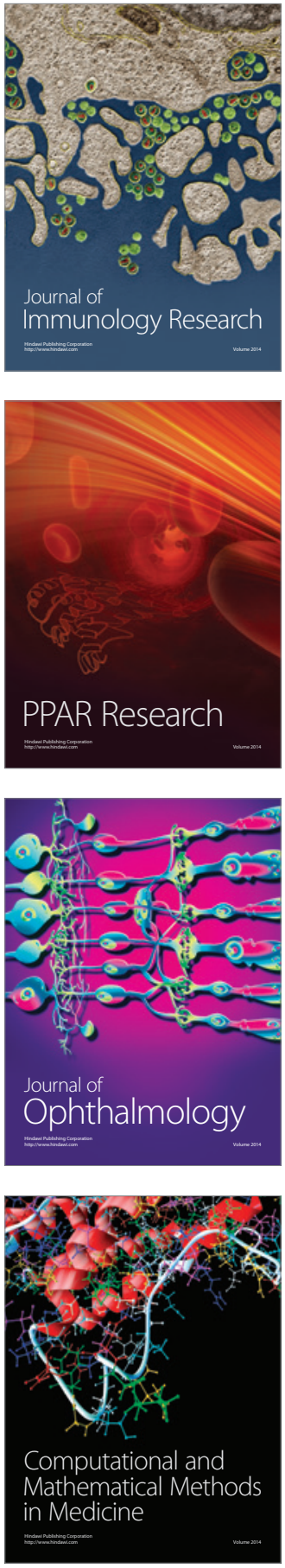

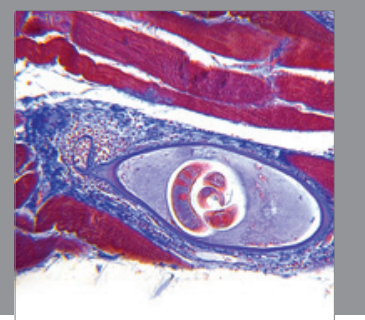

Gastroenterology

Research and Practice
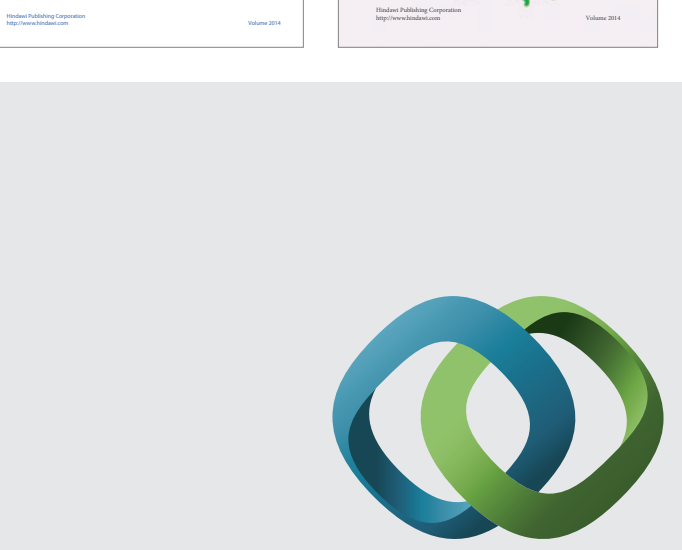

\section{Hindawi}

Submit your manuscripts at

http://www.hindawi.com
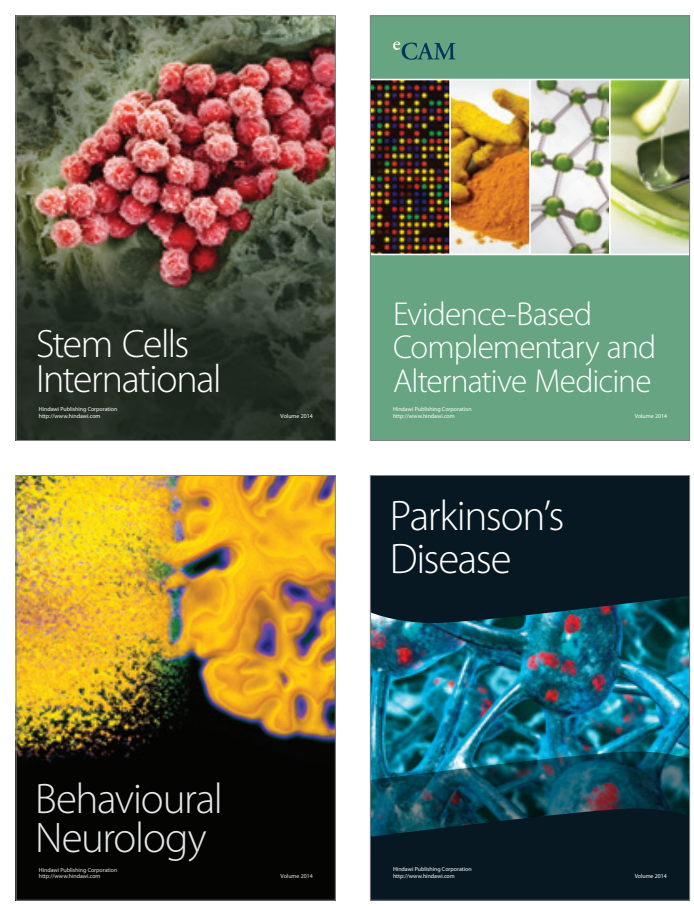

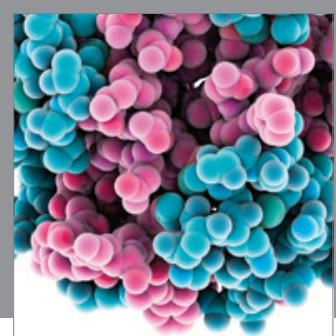

Journal of
Diabetes Research

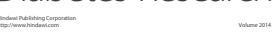

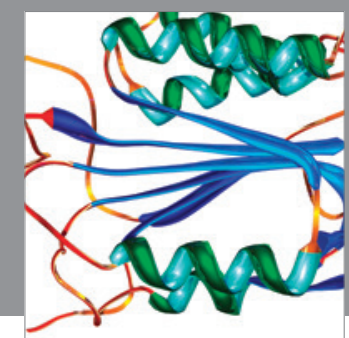

Disease Markers
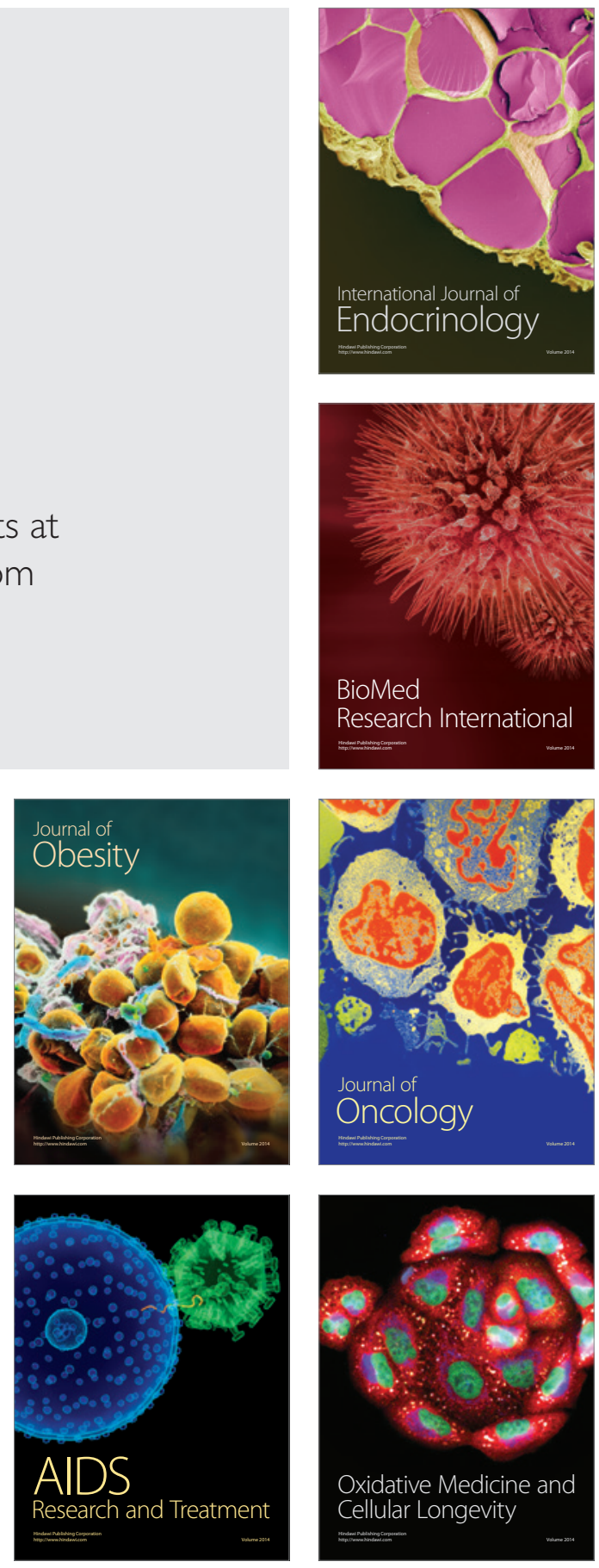